\title{
O TERMINOLOŠKI PROBLEMATIKI V SLOVENSKI GEOGRAFIJI
}

na izbranih primerih

Darko Radinja*

IZVLEČEK

UDK 910.1:001.4

Članek prinaša teoretiXno razmišljanje o kompleksni pomembnosti termina pokrajine in o nekaterih sorodnih terminih.

\section{ABSTRACT}

UDC 910.1:001.4

ABOUTH TERMINOLOGICAL PROBLEMS IN SLOVENE GEOGRAPHY

The article deals with theoretical thoughts abouth the complex mcaning of the therm landscape and some others geographical therm

V slovenski geografiji smo zaceli uporabljati nekatere osnovne termine kratkomalo kot aksiome, kar velja celo za osnovni predmet geografske vede. Zanj uporabljamo vec izrazov, ne da bi bilo docela jasno, ali gre za sinonime ali za pomenske razlike, in tudi ne, $v$ cem naj bi te bile. Še zlasti gre za vprasanje, ali so novi termini povezani z razvojem stroke, njenim sirjenjem ali z njenim morebiti spremenjenim težišcem, ali pa s cim drugim. Ker gre velikokrat za izraze, ki smo jih prenesli od drugod, věasih brez utemeljitve, kar v znanosti sicer ni običajno, bi bile obrazložitve zaradi različnih geografskih కol (nacionalnih), ki se pojavljajo v svetu toliko nujnejše. Ta problematika je zato $\mathrm{v}$ slovenski geografiji nemara క̌ bolj odprta in pereča kakor $\mathrm{v}$ geografski znanosti nasploh.

Med osnovnimi termini so $v$ ospredju zlasti navidezni sinonimi, kakrకnni so npr. pokrajina-okolje-prostor-kompleks-sistem, oziroma, ce smo natancnejsi, geografska pokrajina-geografsko okolje-geografski kompleks (geokompleks)-geografski sistem (geosistem)-geografski prostor (geoprostor). Poleg omenjenih izrazov, ki se nanašajo predvsem na regionalno razsežnost, velja podobno tudi za ustrezne ternine s planetarno razsežnostjo: geografska sfera (geosfera)-pokrajinska sfera- ckoloßka sfera (ekosfera)-bioloł̌ka sfera (biosfera)-prostorska sfera.

Kadar strokovni izrazi izvirajo iz splošnih, podobno kakor pri večni pravkar omenjenih, je seveda živo vprašanje, v cem so pojmovne razlike med njihovo splošno in ožjo strokovno rabo, med pojmovanjem $v$ znanosti nasploh ali $v$ geografiji posebej in med pojmovanjem v drugih, zlasti geografiji sorodnih vedah.

\footnotetext{
*Dr., univ.prof., Oddelek za geografijo, Filozofska fakulteta, 61000 Ljubljana, Aškerčeva 12, YU.
} 
Najprej bi kazalo opozoriti na razliko med pojmoma pokrajina in okolje. Za ozna飞evanje predmeta geografije se namreð pri nas そedalje pogosteje uporablja drugi termin, Ceprav navadno v določnejßi obliki (geografsko okolje). Iz znanstvene sfere je izraz zašel tudi v geografske uxbenike, tako osnovnosolske kakor srednjesolske, kljub tedaj izraženim pomislekom katedre za metodiko geografije pa tudi nekaterih drugih (Gams, 1977). A ker je కel razvoj spontano, drugi termin cedalje bolj izpodriva prvega. Oba se sicer v marsixem prekrivata, predvsem v materialnem oziroma prostorskem pogledu, vendar so glede osnovnega pristopa in vidika med njima tudi naclne razlike, ki jih ne bi smeli prezreti.

Ne gre torej samo za to, da bi gcografsko okolje uveljavljali kot sodobnejši sinonim za pokrajino (Ileši, 1962), temve` je po njegovi rabi mogođe sklepati, da se z njim prestavlja tudi težišce geografije, in sicer na antropocentrično stran, ne morda na bioloకko, kakor bi pri okolju pricakovali. Pravzaprav gre pri tem za socioekonomsko osredotoð̌enost geografije. To pa je pri uporabi tega termina naslednji nesporazum, kajti tovrstna interpretacija okolja se tudi $z$ vidikom humane ekologije ne sklada.

Ko govorimo o pokrajini kot predmetu geografije (ali njenih sinonimih, kakor so geokompleks, geosistem, teritorialni sistem), ne kaže prezreti, da gre pri pokrajini in okolju sicer za iste (pokrajinske) elemente, a za drugačn vidik in đrugačne notranje povezave.

Tovrstne razlike med obema terminoma najlaže ponazorimo $z$ dvema, razmeroma enostavnima mocicloma (risba). Míedtem ko je za model pokrajine (A) znacilna nacelna cnakost vseh elementov in zvez, je za model okolja (B) karakteristiðno, da so povzave usmerjene oziroma osredotocene med faktorji okolja kot objektom na eni strani ter med njegovim biotiðnim središem kot subjektom na drugi; slednji je tudi glavni, osrednji element modela. Pri okolju so, skratka, v cspredju subjekt-objektni odnosi, pri pokrajini pa so zaradi njihove enakopravnosti enako pomembni eni in drugi, subjekt-objektni in objckt-objektni. Modela potemtakem nista istovetna in tako tudi ne termina, ki ju oznacujeta.

Prikazana modela opozarjata šc na naslednjo razliko med pokrajino in okoljem, ki je prav tako nacelne narave. Medtem ko je pokrajina teritorialno sklenjena, zaokrožena in omejena (kar ponzarja sklenjen obris modela A), jc okoljc nesklenjeno, odprto in teritorialno ter strukturno sclektivno, odvisno od subjekta (kar ponazar jajo pretrgan obris modela $\mathrm{B}$, razlǐ̌no oddaljeni objekti in razliŁne zveze med njimi). Za razliko od pokrajine o strukturi in obsegu okolja doloca subjekt. Človekovo okolje se spreminja npr. s stopnjo njegovega razvoja, saj priteguje clovek nove in nove dele pokrajine, ki tako postajajo sestavine njegovega okolja. 
Pokrajine potemtakem ne kaže nadomešati z (geografskim) okoljem kot osrednjim predmetom geografije, kajti med njima so poleg skupnih potez načeine razlike (dimenzijske, strukturne, sistemske). Pað̌ pa kaže okolje kot termin v geografiji uporabljati tedaj, ko gre za ustrezen geografski pogled na pokrajino. Ta vidik pa naj ne bi bil le splošno ekoloski, temveð specifixno geografski. Zlasti tedaj, ko je subjekt okolja družba, vendar v socialnem in biološkem pomenu hkrati.

Tretji pojem, ki ga kot sinonim cedalje pogosteje uporabljajo za pokrajino in okolje je prostor, ceprav je kot termin veliko presplošen, vse preve` generiðen, da bi mu v geografiji lahko dali, vsaj kakor se pri nas uporabija, doloðnejł̧i pomen in s tem ustrezno terminolosko oznako, pa ‘eprav ga doloð̌neje oznað̌imo (gcografski prostor). Pokrajina in okolje sta seveda prostorska pojma, s to razliko, da je prvi dimenzijsko doloそ̌nejßi od drugega. Sicer je prostor v abstraktnem pojmovanju še manj geografski termin kakor so npr. geografski pogled (vidik), geografsko stališe, geografsko pojmovanje. Prenasamo ga iz prostorskih ved oziroma "earth science". Navsezadnje pa je tako, ce je geografija veda o povr $̌ j u$, njen predmet ne more biti prostor.

Medtem ko $\mathrm{z}$ arealom navadno pojmujemo ploskovno razprostranjenost dolocenih pojavov, ki jih v sosedstvu ni, pa se prostor pojmuje veliko bolj neenotno in megleno. Zato ni nakljuxje, da se je njegova raba nasploh, v geografiji pa క̌ posebej, mǒ̌no razŠirila. S prostorom namreð̌ ne moremo "zgreŠiti".Zadoša, da ga oznað̌imo po središcu, medtem ko se v omejitev ni treba spuščati, npr. ljubljanski prostor, industrijski prostor. Ne uporabljajo ga zgolj dimenzijsko, temvex tudi strukturno. Iz sobesedila je sicer mogoce marsikdaj sklepati, za kaj gre, se veckrat pa smo v dvomu. Zato bi kazalo v geografiji, Ceprav je "prostorska veda", rabo "prostora" omcjiti na razumno mero, presplošne pa so trditve, da je prostor predmet geografije. Tudi tedaj, ko regionalno razsežnost prostora raztegnemo na planctarno, smo v zadregi: v kakకnem odnosu naj bi bila prostorska sfera do geosfere, biosferc itd., kolikor ne govorimo pleonastiæno, npr. prostorska gcosfera itd. Tu sploh ne grc za osporavanje prostorskega vidika, ki je za geografijo nedvomno osrednji, primarni, v primerjavi z zgodovinskim (procesološkim) in drugimi, pað pa je nesmiselno rodovno oznako prostora zamenjevati za vrstno. Torej ne gre za prostorsko kompicksnost, marveð za pokrajinsko, ne za prostorsko-tvorne elemente, temvec za pokrajinotvorne. In కe to, kakor je razlika med pokrajino in prostorom.

Če se vrnem $\mathrm{k}$ pokrajini kot terminu, je treba vendarle priznati, da mu posamezne geografske sole pripisujejo razliŁen pomen. Od skoraj tako splošncga, kakor je prostor, do veliko dolođnejšcga. Ponekod se nanaక̌a ra rehierarhicno pokrajino, drugod pa ji pripisujejo dolocen rang, recimo za elementarno pokrajino. Pojmujejo jo bodisi izkljuðno naravnogeografsko, npr., v sovjetski geografiji (Armand 1975), bodisi antropogeografsko, npr. v nemški geografiji (Neef 1967). Ne obstajajo le naziranja o pokrajini kot enoti, temvec tudi kot poljubnem izseku zemeljskega površja. Ponekod pa je v v ospred ju le tipolosko pojmoranje pokrajine. 


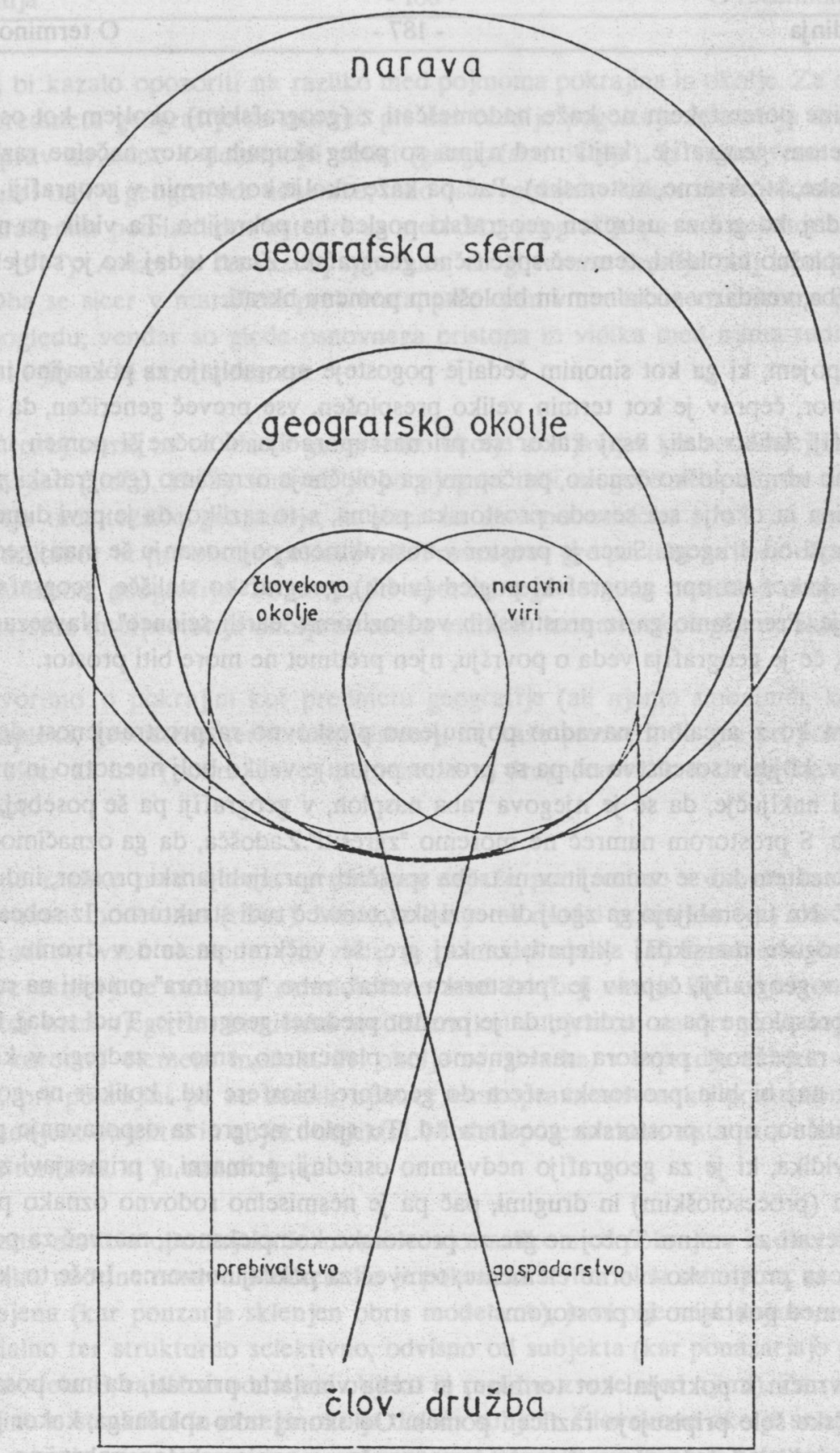

Razlike med pojmi: narava, geografska stera, geogr. okolje, človekovo okolje, naravni viri 
Vsem tem naziranjem je skupna težnja po določnejsi terminoloski opredelitvi pokrajine, vse pa imajo pomanjkljivost, da ji jemljejo univerzalnost (generiðnost), ceprav se ta ohranja, vsaj posredno, ko gre za izpeljanke (naravna pokrajina, antropogena pokrajina, elementarna pokrajina itd.).

Drugo so prizadevanja, da se pokrajino sploh nadomesti $z$ drugim terminom. Pri tem se je vCasih težko znebiti vtisa, da v zamenjavo sili mnenje, ces, da je pokrajina terminoloßko preveđ arhaißna in preprosta. Odtod prizadevanja, da naj bi bilo bistvo geografije zapopadeno že $\mathrm{v}$ samem terminu, ki opredeljuje njen predmet. Temu ustrezna je opredelitev geografskega predmeta kot gcokompleksa (poudarjena kompleksnost) ali geoistema (poudarjena sistemskost) (Soðava, 1963).

Drugi razlog za iskanje novega, za sodobno geografijo pripravnejšega termina, je nemara pomanjkanje ustreznih splošnih izrazov v posameznih knjižnih jezikih, odkoder bi bilo mogoce termin izpeljati. Zato so si marsikje geografi izposodili latinsko areo (areal) v pomenu kraj, ploskev, prostor, ozemlje, pokrajina, ali pa Landschaft (Land + sifiks, ki označuje soodvisnost, povezanost). Vzporejamo ga labko z Landscape. Podobno je s slovensko "pokrajino". Tudi ta ima za osnovo "kraj", ki s predpono (po-) in obrazilom (-ina) oznacuje teritorialno razsežnost in njeno celovitost, podobno kakor je npr. izpeljano ozemlje, pore`je ali povodje (od zemlje, reke in vode).

Pokrajina kot termin potemtakem povsem ustreza, vsebinsko in jezikovno, za oznarevanje geografskega predmeta.* Hkrati je zanjo znaxilna tudi živa in spodbudna tradicija. Pokrajino velja zato v gcografiji obdržati kot osnovni terminološki pojem, in sicer ne glede na njeno hicrarhijo ali strukturo, torej za dimenzijsko in vsebinsko razlǐ̌ne pokrajine - naravne, antropogene, tipoloske in druge. Pokrajino lahko brez zadrege vzporejamo tudi z mlajšmi, učenjaško nemara bolj zveneとimi, širše pojmovanimi termini - s teritorialnim kompleksom, geokompleksom in geosistemom.

Prva dva termina (teritorialni kompleks, geokompleks) sta vpeljana, da bi podcrtala kompleksnost geografskega objekta, tretji (geosistem) pa zato, da poudari njegovo sistemsko naravo. Zaradi slednjega bi bilo mogoce prva dva termina sploh opustiti, saj vsebuje njuna poudarka v celoti. Osebno sicer menim, da vsi trije termini prav zaradi tega, ker poudar jajo doloðene vidike, Ceprav so osrednji, zlasti zadnji, izgubljajo del pojmovne kompleksnosti, saj je pokrajina tudi zunanja podoba, skratka pejsaž, ki svoj pomen v geografiji కe vedno ohranja.

"Glede pomenske problematike obeh jezikovno sorodnih izrazov "pokrajina" in "krajina", ki je bila med drugim sprožena tudi v Geografskem vestniku (Ogorelec, 1987), tu ne kaže razpravljati, ker gre za ožje vprašanje, li bo tako in tako obravnavano v naslednji številki omenjene revije. 
Pri pokrajini, ¿e se ponovno vrnem $\mathrm{k}$ njej, naj omenim \̌e njeno planetarno razsežnost. Vse pokrajine, enostavno receno, sestavljajo pokrajinsko sfero. Ta je njihova celokupnost. Ali drugađe, pokrajinska sfera je pokrajina najvisjega ranga. V primerjavi $\mathrm{z}$ geosfero je njena prednost, $\mathrm{ker}$ je $\mathrm{v}$ njenem ospredju vertikalna in $\mathrm{s}$ tem sintetiena struktura, ne pa horizontalna oziroma analitixna, kakor pri geosferi. Z njo namrex poudarjamo, da sestavljajo geosfero relativno samostojni deli, pojmovani kot regije.

Pri predavanjih fiziðnc geografije sem nekdaj studente seznanjal s pojmom in definicijo pokrajinske sfere. Dimenzijsko sem jo sicer stel za sinonim geosfere, vendar s pomembno naxelno razliko zaradi vertikalnega principa razčlenjevanja pri eni in horizontalnega pri drugi. Na pokrajinsko sfero gledam danes nckoliko drugace. Ker se debelina pokrajin ne ujema $z$ debelino geosfere, saj te ne segajo $\mathrm{v}$ najvišje dele atmosfere ali litosfcre, je pokrajinsko sfero mogoče steti za jedro geosfere, ki je dimenzijsko bližja biosferi, ce jo ne razumemo $v$ ožjem pomenu (șvet živih organizmov), temveð $v$ Šrš̌m ( $z$ njihovimi življenjskimi pogoji vred). $S$ tako pojmovano biosfero je identǐna ekosfera (ekoloßka sfera), to je sfera aktivnosti živih organizmov in njihovega okolja. Ekosfera je potemtakem ekosistem najvišjega ranga. Gre za podobno razmerje, kakor med pokrajinsko sfero in pokrajino, oziroma gcosfero in geosistemom.

Toda za primer javo teh sfer ni bistvena prostorska podobnost ali identǐnost, bistvene so vsebinske razlike (strukturne, sistemske), kar je posledica razlienih izhodiš in vidikov. Tu sc kažejo pomembne razlike med geografskimi in ekoloskimi pogledi. Z grafixnim modelom prikazana vsebinska razlika med pokrajino in okoljem ne velja le regionaino, temve` tudi planetarno. Geosfera zato ni istovetna z ekosfero, ker so tu in tam v ospredju drugarne povezave med komponentami. Geografski vidik je zato principialno razliðen od ekoloskega in tako tudi obe vedi. Enako velja za humano ekologijo in pokrajinsko ekologijo. Drugare bi bilo $\mathrm{z}$ ekološko geografijo kot delom geografije.

Ko imamo v mislih usmerjenost povezav med komponentami pokrajine, je ekoloskemu vidiku bližja pravzaprav družbena geografija kakor fizix̌na, zlasti antropocentrična. Razlika je v kakovosti povezav. Medtem ko je tu v ospredju socio-ckonomska narava, je tam biološka. Nasprotno je fiziðna geografija bližja ekologiji po kvaliteti povezav, manj pa po njihovi usmerjenosti. $\mathrm{Za}$ regionalno geografijo so značilne obojne poteze.

Nekatera terminološka vprašanja so v geografiji živa tudi zaradi sorodne naravovarstvene, okoljevarstvene in ekooške terminologije, se zlasti zaradi tovrstnih interdisciplinarnih raziskovanj. Preciziranje nekaterih geografskih terminov ni potrebno toliko 
zaradi klasiŁnc, biološke ekologije, kolikor zaradi sirše pojmovane humane ekologije. Pri tem pa naj ne bi šlo za težnje po unificiranju terminologije, temveð za osvetlitev razlik, sorodnosti ali enakosti, posebno glede razlixnega pomena istih terminov oziroma istega pomena razlixnih.

Znaxilno je, da so se bioloski termini na Siroko uveljavljajo pri varstvu narave kot splošno znanstvenem podrołju, kar je ocitno posledica tega, da so naravovarstvo dolgo Casa obravnavali kot varstvo žive narave (rastlinstva in živalstva). Odtod tcžnja oziroma praksa, da vrsto bioloßkih pojmov obravnavajo kot sploకno znanstveno, medtem ko "sorodne" geografske termine stejejo kvě̌jemu za sinonime. Če pa analiziramo ustrezne pare takih terminov, se kažejo znaxilne razlike.

Takšna terminološka dvojica, omenjena doslej že v drugi zvezi, sta npr. biosfera in geosfera. Klasiðno pojmovanje, ki steje biosfero kot sfero živih organizmov, jo pojmuje kot eno od sfer Zemlje, torej kot komponento geosfere, toda v ekološki literaturi, posebej naravovarstveni in ponekod tudi geografski (?!), se pojavlja kot sinonim geografske sfere; torej komponenta v funkciji celotc. Oxitno je, da gre za razSirjeno pojmovanje biosfere. Pri tem pa biosfcra, kot že omenjeno, nastopa kot obとe znanstveni termin, geosfera pa le kot soroden "sinonim". Tudi ce obe sferi prostorsko istovetimo, ostaja med njima bistvena razlika, saj je biosfera pravzaprav biocentrixna selekcija geosfere. Nacelna razlika med obema pojmoma je torcj nedvomna, saj je pri geosferi med drugim težišce na soodvisnosti posameznih komponentnih sfer, med drugim tudi kot pogoju za življenje. Pri geografski obravnavi biosfere pa tudi na njeni vlogi, ki jo ima p ri transformaciji drugih sfer - pri biogeni sestavi atmosfere, hidrosfere, pedosfere in litosfcre. Zato je že pojmovanje biosfere geografsko in biološko različno, toliko bolj pa pojmovanje biosfere in geosfere. Termina nista zato niti najmanj sinonima, zaradi razlik pa ju je seveda treba obdržati, saj se dopolnjujeta, ne pa nadomešcata. $\mathrm{V}$ geografiji zato okolje ne more zamenjati pokrajine in biosfera ne geosfere, v ekologiji pa ne obratno.

Razvoj znanosti seveda ni edini vzrok za spreminjanje njenega jezika. Nanj pogosto vplivajo spremenjene funkcije pojavov, ki so predmet proucevanja. S tem v zvezi so med splošnimi geografskimi termini znaxilni npr. naravni pogoji-naravni viri- naravne danosti.

$\mathrm{Z}$ naravnimi pogoji razumemo razmere, ki so nujne za obstajanje ali spreminjanje cesarkoli ali karkoli. Bistveni so npr. za življenje in deovanje človeške družbe, vendar $v$ gospodarstvo (materialno proizvodnjo) niso neposredno zajeti. $Z$ naravinimi viri pa razumemo prav to. Enostavno povedano, naravni viri so vse, kar Clovek "proizvodno" jemlje iz narave. Na sedanji razvojni stopnji se to dogaja Cecialje bolj celovito. To pomeni, da se pogoji spreminjajo v vire. Klasično razčlenjevanje naravnih pojavov na 
dve skupini (na pogoje in virc), znaxilno za geografijo pa tudi ekonomijo, je zato danes že zastarelo, saj upraviðeno govorimo o Łirokem, vsesplošnem spreminjanju naravnih pogojev $\mathrm{v}$ integralni kompleks virov. Tak, intenzivno obdelovalni vir ni le zemlja, temveð npr. tudi atmosfera, saj že krepko uporabljamo njene kemix̌ne in fizikalne lastnosti, še posebno akustið̌ne, optið̌ne, elektromagnetne, biološke in druge. Pokrajinsko sfero je clovesttvo spremenilo takorekot v skupni naravni vir, saj se dejansko izkorišcajo že vsi clementi narave. Zato je degradacija pokrajinske sfere, izraženo geografsko, ali okolja, izraženo ekološko, vsesplošna.

Tretji izraz, ki je s tem v zvezi - naravne danosti -, je vprasljiv najprej zaradi samega odnosa cloveka do narave, ki ga termin simbolizira (narava naj bi bila cloveku dana?). Posledica takega odnosa so kritiki cedalje bolj izpostavljene. Drugi pomislek je chlapnost termina. Danosti pojmujejo razlixno, vecinoma kot vire, pogosto pa tudi kot pogoje, oziroma kot eno in drugo.

Izbrani primeri ilustrirajo, kako je geografska terminologija $v$ marsikem odprta, kar je posledica marsixesa, bodisi premalo kritixne geografske misli sploh, š v vecji meri pa Sirjenja in drobljenja geografske znanosti. Hitreje se zato razvija in izpopolnjuje terminologija posameznih geografskih vej, manj pa pojmi in termini teoregixne in naxelne strani gcografije kot cclote. Podobno velja za terminologijo skupne fizixne in skupne družbene geografije (ne zgolj kot vsota ustreznih vej), in seveda regionalne. Sistcmaticna skrb za razvoj celotne geografske terminologije je preveð zanemarjena. Ni nakljuxje, da je pregled geografske terminologije, ki se v zadnjem casu pripravlja v okviru SAZU, naletel na tolikšne težave. Ne bi smeli dopustiti, da bi razdrobljena tcrminologija zmanjłala razumevanje znotraj geografije in postala ovira za njeno uveljavljanje navzven.

Bolj kot normativna terminologija je potrebna primerjalna, oziroma interpretacijska, zlasti zaradi rabe razlixnih terminov za iste ali sorodne pojme ter pomenskih razlik enih in istih terminov. 


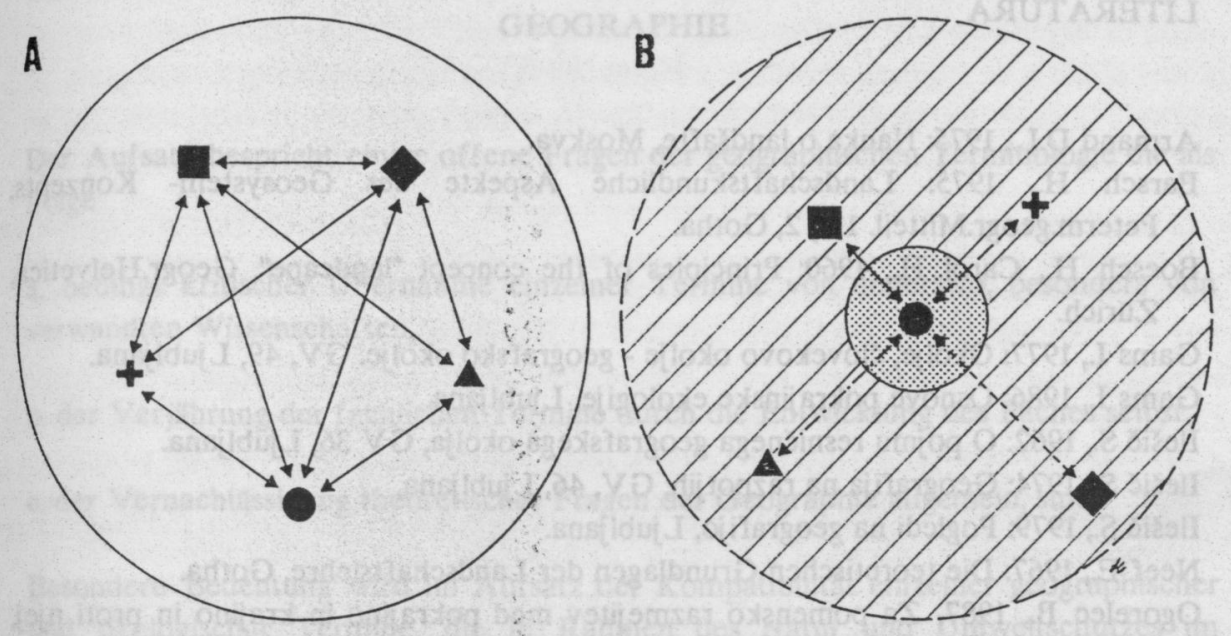

POJMOVNE RAZLKE MED POKRAJINO IN OKOLJEM (geosistemom in ekosistemom)

A pokrajina (geosistem)

B okolje (ekosistem)

A abiotične komponente

+ biotične komponente

$\longleftrightarrow \quad$ zveze med komponentami $v$ pokrajini

$\stackrel{\longrightarrow}{\longrightarrow}$ zveze med komponentami v okolju

. podsistem osredini element" (subjekt); prostor (maritorialno sklenjen)

PIA podsistem okolje (objekt); prostor (teritorialno nesklenjen) 


\section{LITERATURA}

Armand D.L., 1975: Nauka o landsafte, Moskva.

Barsch H., 1975: Landschaftskundliche Aspekte des Geosystem- Konzepts, Peterm.geogr.Mitteil. 119, 2, Gotha.

Boesch H., Carol H., 1960: Principles of the concept "landcape". Geogr.Helvetica, Zürich.

Gams I., 1977: Okolje, človekovo okolje - geografsko okolje. GV, 49, Ljubljana.

Gams I., 1986: Osnove pokrajinske ekologije, Ljubljana.

Ilešix S., 1962: O pojmu resnixnega geografskega okolja, GV 36, Ljubljana.

IleŠi S., 1974: Geografija na razpotjih, GV, 46, Ljubljana.

Ilešix S., 1979: Pogledi na geografijo, Ljubljana.

Neef E., 1967: Die teoretischen Grundlagen der Landschaftslehre, Gotha.

Ogorelec B., 1987, Za pomensko razmejitev med pokrajino in krajino in proti njej, GV, 59, L jubljana.

Socava V.B., 1963, Opredelenie nekotoryh ponjatij i terminov fiziceskoj geografii, Novosibirsk.

Vrišer I., 1976: Uvod v geografijo, Ljubljana.

1961, Glossary of Geographical Therms, London.

1978, Geographie, Herder Lexikon. 


\section{ÜBER DIE PROBLEMATIK DER TERMINOLOGIE IN DER SLOWENISCHEN GEOGRAPHIE}

Der Aufsatz bespricht einige of fene Fragen der geographischen Terminologie die als Folge

a. bedingt kritischer Übcrnahme einzelner Termine von anderswo, besonders von verwandten Wissenschaften,

b. der Verjăhrung der fachlichen Termine durch die Entwicklung des Faches selbst,

c. der Vernachlässigung theoretischer Fragen der Geographie allgemein, sind.

Besondere Bedeutung wird im Aufsatz der Kompatibilităt einzelner geographischer und okologischer Termine, die in Rahmen des Natur und Umweltschutzes im Gebrauch sind, zugemessen. Dabei wird auf die begriffliche Verwandschaften hingewiesen, es werden aber auch die prinzipiallen Unterschiede der einen und der anderen (die Landschaft - die Umwelt, die Geosphăre- die Biosphăre) erlăutert.

Der Aufsatz weist auf die ungleichmässige Entwicklung der geographischen Terminologie, die besser in cinzclnen Fachdisziplinen als im Rahmen der zentralgcographischen entwickelt wird, auf. Auf dem Beispiel "der Landschaft" werden Unterschiede die zwischen einzelnen nationalgeographischen Schulen existieren gezeigt. 